\title{
Acylation of nitriles to $\beta$-ketonitriles catalyzed by a heterometallic alkoxide cluster of neodymium and sodium: $\mathrm{NdNa}_{8}\left(\mathrm{O}^{t} \mathrm{Bu}\right)_{10}(\mathrm{OH})$
}

\author{
LIU HaiDong ${ }^{1}$, LI Lan $^{1}$, SHENG HongTing $^{1}$, ZHU XueHua $^{1}$, XU Fan $^{1 *} \&$ SHEN Qi $^{12^{*}}$ \\ ${ }^{1}$ Key Laboratory of Organic Synthesis of Jiangsu Province, College of Chemistry, Chemical Engineering and Materials Science, Soochow \\ University, Suzhou 215123, China; \\ ${ }^{2}$ State Key Laboratory of Organometallic Chemistry, Shanghai Institute of Organic Chemistry, Chinese Academy of Sciences, \\ Shanghai 200032, China
}

Received July 20, 2010; accepted November 4, 2010

\begin{abstract}
Catalytic acylation of nitriles with esters in the presence of $10 \mathrm{~mol} \% \mathrm{NdNa}_{8}\left(\mathrm{O}^{t} \mathrm{Bu}\right)_{10}(\mathrm{OH})$ is developed. The procedure is suitable for both enolizable and nonenolizable esters and affords $\beta$-ketonitriles in moderate to high yields. The heterometallic alkoxide cluster $\mathrm{NdNa}_{8}\left(\mathrm{O}^{t} \mathrm{Bu}\right)_{10}(\mathrm{OH})$ is structurally characterized by X-ray diffraction, and a mechanism for the production of $\beta$-ketonitriles using the cluster is proposed and verified.
\end{abstract}

acylation, $\beta$-ketonitrile, catalysis, lanthanides, heterometallic complex, cluster

Citation: $\quad$ Liu H D, Li L, Sheng H T, et al. Acylation of nitriles to $\beta$-ketonitriles catalyzed by a heterometallic alkoxide cluster of neodymium and sodium: $\mathrm{NdNa}_{8}\left(\mathrm{O}^{t} \mathrm{Bu}\right)_{10}(\mathrm{OH})$. Chinese Sci Bull, 2011, 56: 1357-1360, doi: 10.1007/s11434-011-4451-x

$\beta$-ketonitriles are useful precursors for the synthesis of a variety of heterocyclic compounds including dihydropyrans, dihydrothiopyrans, pyrazoles, pyridones and imidazoles, as well as specific ketones upon decyanation [1]. Several methods for the synthesis of $\beta$-ketonitriles have been reported [2-7]. One of the most simple and direct approaches is the acylation of nitriles exploiting the acidity of the protons adjacent to the nitrile group. The initial acylation with sodium amide in liquid ammonia [8] gave higher yields than that with sodium alkoxide [9]. However, the route using sodium amide is accompanied by inherent hazards. Recently, the acylation of nitriles with unactivated esters using lithium diisopropylamide (LDA) or sodium hydride $(\mathrm{NaH})$ as a base [10] and with activated $\mathrm{N}$-acylbenzotriazoles using $n$-butyl lithium $\left({ }^{n} \mathrm{BuLi}\right)$ or potassium tert-butoxide $\left(\mathrm{KO}^{t} \mathrm{Bu}\right)$ [11] were developed. Very recently, the reaction of sterically hindered nitriles with enolizable and nonenolizable esters was successfully achieved using 3 equiv. of potassium tert-amoxide $\left(\mathrm{KO}^{t} \mathrm{Amyl}\right)$ giving the corresponding

*Corresponding authors (email: xufan@ suda.edu.cn; qshen@suda.edu.cn) $\beta$-ketonitriles in high yields [12].

Recently we found that the clusters $\left[\mathrm{Ln}_{2} \mathrm{Na}_{8}\left(\mathrm{OCH}_{2} \mathrm{CH}_{2}-\right.\right.$ $\left.\left.\mathrm{NMe}_{2}\right)_{12}(\mathrm{OH})_{2}\right](\mathrm{Ln}=\mathrm{Nd}, \mathrm{Pr}, \mathrm{Sm}, \mathrm{Y}, \mathrm{Ho})$ are active singlecomponent catalysts for the polymerization of e-caprolactone as well as trimethylene carbonate. The reactivity of these clusters is much higher than those of the related lanthanide alkoxide and sodium alkoxide compounds, indicating that a cooperative effect may exist between the two different metals in these ring-opening polymerization reactions [13]. These results encouraged us to study further the application of heterometallic alkoxide clusters containing lanthanide and sodium in organic synthesis. Here, we report the synthesis of heterometallic tert-butoxide clusters containing lanthanide and sodium $\mathrm{LnNa}_{8}\left(\mathrm{O}^{t} \mathrm{Bu}\right)_{10}(\mathrm{OH})(\mathrm{Ln}=\mathrm{Nd}, \mathrm{Sm}, \mathrm{Yb})$ and their catalytic activity for the acylation of nitriles with esters.

\section{Experimental}

\subsection{General remarks}

All experiments were performed under argon, using 
standard Schlenk techniques. All solvents were distilled from sodium benzophenone ketyl prior to use. Nitriles and esters were dried over $\mathrm{CaH}_{2}$ before being distilled. Melting points were uncorrected. ${ }^{1} \mathrm{H}$ and ${ }^{13} \mathrm{C}$ NMR spectra were obtained on Varian INOVA-400 spectrometer using tetramethylsilane as an internal reference. High resolution mass spectrometry (HRMS) data were obtained on a Micromass GCT spectrometer. New compounds were fully characterized by ${ }^{1} \mathrm{H}$ and ${ }^{13} \mathrm{C}$ NMR spectroscopy and HRMS.

\subsection{General procedure for $\mathrm{NdNa}_{8}\left(\mathrm{O}^{t} \mathrm{Bu}\right)_{10}(\mathrm{OH})$ catalyzed acylation of nitriles}

A solution of $\mathrm{NdNa}_{8}\left(\mathrm{O}^{t} \mathrm{Bu}\right)_{10}(\mathrm{OH})(107.52 \mathrm{mg}, 0.10 \mathrm{mmol})$ in toluene $(3 \mathrm{~mL})$ was added dropwise to a solution of a nitrile $(1 \mathrm{mmol})$ in THF $(3.4 \mathrm{~mL})$. The appropriate ester $(4$ $\mathrm{mmol}$ ) was then added dropwise. The mixture was stirred at $60^{\circ} \mathrm{C}$ for a given time, and then diluted with $\mathrm{HCl}(0.25$ $\mathrm{mol} / \mathrm{L}, 100 \mathrm{~mL})$ and EtOAc $(100 \mathrm{~mL})$. The organic layer was separated and washed sequentially with $\mathrm{H}_{2} \mathrm{O}(2 \times 50$ $\mathrm{mL})$ and brine $(2 \times 50 \mathrm{~mL})$, dried over anhydrous $\mathrm{Na}_{2} \mathrm{SO}_{4}$, concentrated in vacuo and purified by column chromatography on silica gel (eluent: EtOAc/petroleum ether) to afford the appropriate $\beta$-ketonitrile.

\section{Results and discussion}

Clusters of $\mathrm{LnNa}_{8}\left(\mathrm{O}^{t} \mathrm{Bu}\right)_{10}(\mathrm{OH})$ could be synthesized in good yields by the reaction of $\mathrm{LnCl}_{3}(\mathrm{Ln}=\mathrm{Nd}, \mathrm{Sm}, \mathrm{Yb})$ with $\mathrm{NaO}^{t} \mathrm{Bu}$ in the presence of 1 equiv. of $\mathrm{NaOH}$.

$$
\begin{aligned}
& \mathrm{LnCl}_{3}+10 \mathrm{NaO}^{t} \mathrm{Bu}+\mathrm{NaOH} \stackrel{\text { THF }}{\longrightarrow} \\
& \mathrm{LnNa}_{8}\left(\mathrm{O}^{t} \mathrm{Bu}\right)_{10}(\mathrm{OH})+3 \mathrm{NaCl} \\
& \mathrm{Ln}=\mathrm{Nd}, \mathrm{Sm}, \mathrm{Yb}
\end{aligned}
$$

X-ray structural determination of the Nd cluster [14] revealed that it contains one $\mathrm{Nd}$ atom, 8 sodium atoms, 10 $\mathrm{OC}\left(\mathrm{CH}_{3}\right)_{3}$ groups and one $\mathrm{OH}$ group. All of the metal atoms are located at the vertices of a capped square antiprism, with the Nd atom in the capping position (Figure 1), which is as the same as that for the analogous $\mathrm{Y}$ cluster published previously [15].

With the clusters in hand, their reactivity for the acylation of nitriles with esters was examined. The initial condensation of acetonitrile (1) and ethyl benzoate (2a) in THF/toluene (1:1) containing $10 \mathrm{~mol} \% \mathrm{NdNa}_{8}\left(\mathrm{O}^{t} \mathrm{Bu}\right)_{10}(\mathrm{OH})$ at room temperature provided the expected $\beta$-ketonitrile $3 \mathbf{b a}$ in $50 \%$ yield after $3 \mathrm{~h}$. Because of this success, it was decided to optimize the reaction conditions. First, the effect of the molar ratio of each respective reagent was examined using the condensation of benzylnitrile (1a) and ethyl benzoate (2a) as a model reaction (Table 1). It was found that the presence of excess ester could significantly improve the yield and the highest yield was obtained with 1 equiv. of

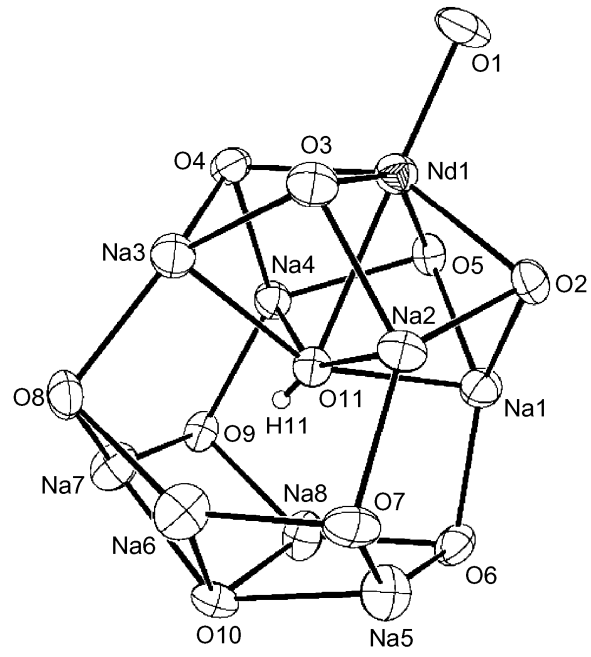

Figure 1 X-ray crystal structure of the cluster $\mathrm{NdNa}_{8}\left(\mathrm{O}^{t} \mathrm{Bu}\right)_{10}(\mathrm{OH})$.

Table 1 The effects of the molar ratio of reagents and reaction time on a model acylation reaction.

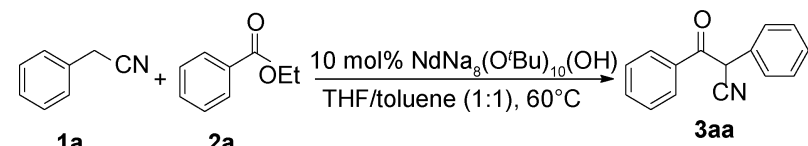

\begin{tabular}{ccccc}
\hline Entry & Nitrile (molar equiv.) & Ester (molar equiv.) & Time (h) & Yield $(\%)^{\mathrm{a})}$ \\
\hline 1 & 1 & 1 & 3 & 30 \\
2 & 1 & 2 & 3 & 52 \\
3 & 1 & 3 & 3 & 62 \\
4 & 1 & 4 & 3 & 84 \\
5 & 1 & 4 & 1 & 58 \\
6 & 1 & 4 & 5 & 80 \\
7 & 1 & 4 & 8 & 74 \\
\hline
\end{tabular}

a ) GC yield using methyl salicylate as an internal standard.

nitrile and 4 equiv. of ester (entry 4). The effect of reaction time on yield was also investigated. The yield increased up to a maximum value after reaction for $3 \mathrm{~h}$ (entry 4 ) and then decreased gradually as time progressed.

The influence of temperature on the model reaction was also studied (Table 2). The reaction progressed slowly at room temperature and a yield of just $38 \%$ was obtained (entry 1). Increasing the reaction temperature to $60^{\circ} \mathrm{C}$ increased the yield to $84 \%$ (entry 2). Further increasing the temperature decreased the yield (entries 3 and 4 ) compared with that obtained at $60^{\circ} \mathrm{C}$. The results demonstrate that a lower temperature may result in incomplete reaction while overheating lead to undesired side reactions such as further condensation. After screening several solvents, it was found that the highest yield was obtained using a mixture of THF/toluene (1:1) (entry 2). Changing the solvent to dimethyl ether (DME) significantly reduced the reaction yield (entry 7).

The influence of the lanthanide ion in the cluster on the acylation reaction was then examined (Table 3). The order of activity observed was $\mathrm{Yb}<\mathrm{Sm}<\mathrm{Nd}$, which reflects the 
Table 2 The effects of reaction temperature and solvent on a model acylation reaction.

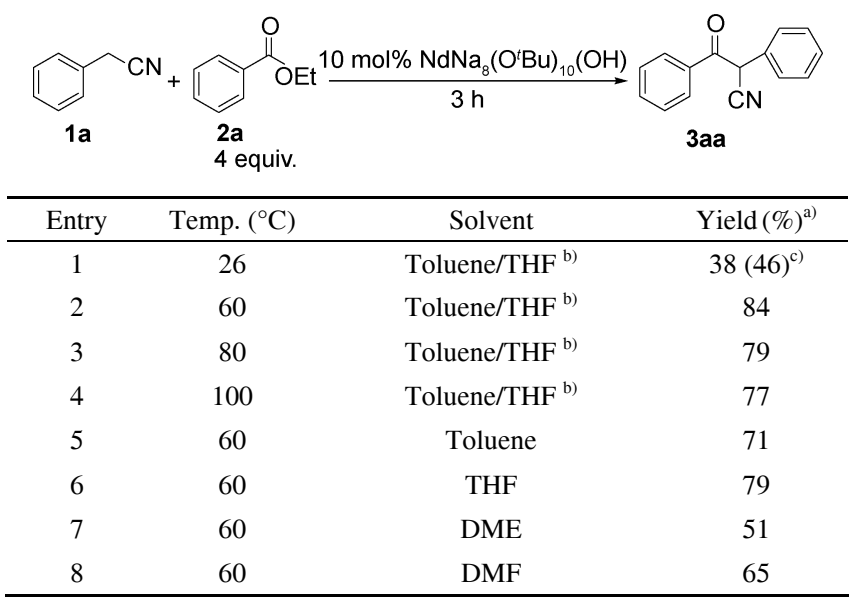

a) GC yield using methyl salicylate as an internal standard. b) Toluene: $\mathrm{THF}=1: 1$. c) After reaction for $12 \mathrm{~h}$.

Table 3 The effect of the rare earth metal ion in the catalyst on a model acylation reaction.

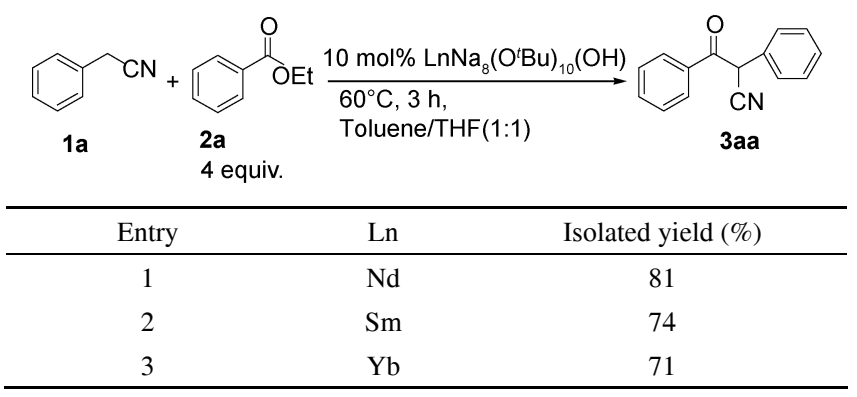

increasing radius of the metal ions, although the differences in the yields obtained were not great.

Upon optimization of the reaction conditions, we examined the scope of the acylation reaction using a variety of nitriles and esters under the optimal solvent, reaction time and temperature conditions with $10 \mathrm{~mol} \% \mathrm{NdNa}_{8}\left(\mathrm{O}^{t} \mathrm{Bu}\right)_{10^{-}}$ $(\mathrm{OH})$ as the catalyst (Table 4$)$. All of the reactions proceeded smoothly and afforded the corresponding $\beta$-ketonitriles in moderate to high yields. A wide range of suitable substrates, including enolizable and nonenolizable esters as well as aryl- and alkyl-substituted acetonitriles, were identified. It should be noted that the enolizable esters $\mathbf{2 d}$ and $\mathbf{2 e}$ gave acceptable yields of $\beta$-ketonitriles using this approach, even though an extended reaction time was required.

To the best of our knowledge, this is the first example of catalytic acylation of nitriles with esters to produce $\beta$-ketonitriles. Undoubtedly, the specific structure of the catalyst is the key factor that determines the success of the reaction. On the basis of the structure determined for $\mathrm{NdNa}_{8}\left(\mathrm{O}^{t} \mathrm{Bu}\right)_{10}(\mathrm{OH})$ [14], a general mechanism for this reaction was proposed (Figure 2). As the first step, an interaction between the oxygen atom of the $\mathrm{C}=\mathrm{O}$ bond and the central $\mathrm{Nd}$ (III) ion occurs, which is driven by the Lewis acidity of
Table 4 Acylation of nitriles with esters under optimized conditions.

\begin{tabular}{|c|c|c|c|c|c|}
\hline \multicolumn{2}{|c|}{$\mathrm{R}^{1} \widehat{\mathrm{CN}}+\mathrm{R}^{2}$} & & \multicolumn{2}{|c|}{$10 \mathrm{~mol} \% \mathrm{NdNa}_{8}\left(\mathrm{O}^{t} \mathrm{Bu}\right)_{10}(\mathrm{OH})$} & \multirow{2}{*}{$\begin{array}{c}\mathrm{R}^{1} \mathrm{C}_{\mathrm{O}}^{\mathrm{C}} \mathrm{CN}-3 \mathrm{cg} \\
\mathrm{R}\end{array}$} \\
\hline \multicolumn{5}{|c|}{$\begin{array}{ll}\mathbf{1 a}, \mathrm{R}^{1}=\mathrm{Ph}- & \mathbf{2 a}, \mathrm{R}^{2}=\mathrm{Ph}- \\
\mathbf{1 b}, \mathrm{R}^{1}=\mathrm{H}- & \mathbf{2 b}, \mathrm{R}^{2}=p-\mathrm{CIPh}- \\
\mathbf{1 c}, \mathrm{R}^{1}=\mathrm{PhCH} 2- & \mathbf{2 c}, \mathrm{R}^{2}=p-\mathrm{MeOPh}- \\
& \mathbf{2 d}, \mathrm{R}^{2}=p-\mathrm{NO}_{2} \mathrm{Ph}- \\
& \mathbf{2 e}, \mathrm{R}^{2}=p-\mathrm{CF}_{3} \mathrm{Ph}- \\
& \mathbf{2 f}, \mathrm{R}^{2}=\mathrm{Et}- \\
& \mathbf{2 g}, \mathrm{R}^{2}={ }^{\prime} \mathrm{Pr}-\end{array}$} & \\
\hline Entry & $\mathrm{R}^{1}$ & $\mathrm{R}^{2}$ & Time (h) & Product & Yield (\%) \\
\hline 1 & 1a & $\mathbf{2 a}$ & 3 & $3 \mathbf{a a}$ & 78 \\
\hline 2 & 1a & $2 b$ & 2 & 3ab & 88 \\
\hline 3 & 1a & $2 \mathrm{c}$ & 3 & $3 a c$ & 70 \\
\hline 4 & 1a & $2 \mathbf{f}$ & 3 & 3af & 73 \\
\hline 5 & 1a & $2 g$ & 6 & 3ag & 78 \\
\hline 6 & $1 b$ & $2 a$ & 3 & $3 \mathbf{b a}$ & 81 \\
\hline 7 & $1 \mathrm{~b}$ & $2 \mathbf{b}$ & 2 & $\mathbf{3 b b}$ & 90 \\
\hline 8 & $1 b$ & $2 c$ & 3 & $3 b c$ & 67 \\
\hline 9 & $1 \mathbf{b}$ & $2 d$ & 3 & 3bd & 78 \\
\hline 10 & $1 \mathbf{b}$ & $2 \mathbf{e}$ & 3 & 3be & 85 \\
\hline 11 & $1 \mathbf{b}$ & $\mathbf{2 f}$ & 12 & $3 b f$ & 72 \\
\hline 12 & $\mathbf{1 b}$ & $2 g$ & 6 & $3 b g$ & 60 \\
\hline 13 & 1c & $\mathbf{2 a}$ & 3 & $3 \mathbf{c a}$ & 68 \\
\hline 14 & $1 c$ & $2 b$ & 2 & $3 \mathrm{cb}$ & 86 \\
\hline 15 & $1 c$ & $2 c$ & 3 & $3 \mathrm{cc}$ & 63 \\
\hline 16 & 1c & $\mathbf{2 f}$ & 48 & $3 \mathrm{cf}$ & 70 \\
\hline 17 & 1c & $2 \mathrm{~g}$ & 24 & $3 \mathrm{cg}$ & 68 \\
\hline
\end{tabular}

the $\mathrm{Nd}(\mathrm{III})$ ion. At the same time, the nucleophilicity of the $\alpha$-carbon atom of the cyano group is increased by deprotonation by the sodium alkoxy moiety of the catalyst [16]. The nucleophilic $\alpha$-carbanion of the cyano group then reacts with the carbonyl group of the ester (A) to form the $\beta$-ketonitrile, accompanied by the release of sodium alkoxide and the active species $\mathbf{B}$. The final step of the catalytic cycle is achieved by proton exchange between sodium

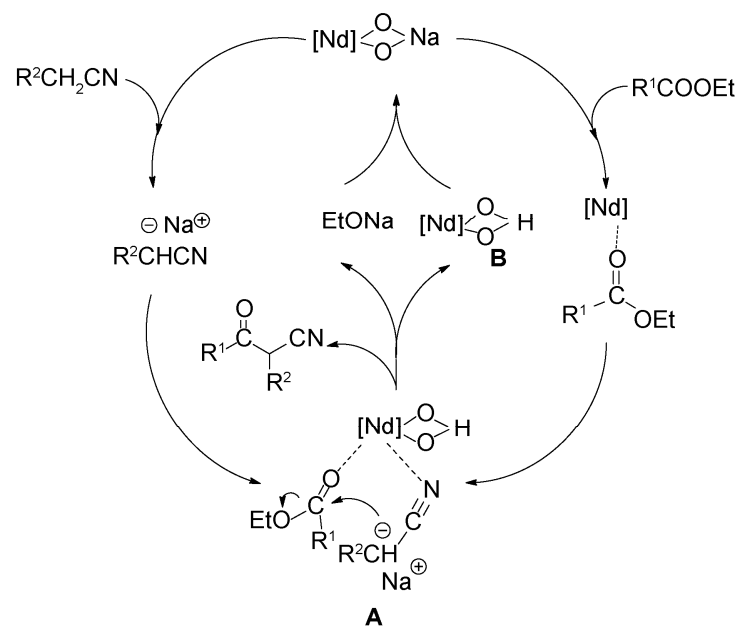

Figure 2 Proposed reaction mechanism. 
alkoxide and the active species $\mathbf{B}$, which regenerates the catalyst. It is likely that the lanthanide metal in the cluster acts as a Lewis acid to active the ester, and the sodium alkoxy moiety functions as a Brønsted base to deprotonate the nitrile. To confirm this mechanism, supplementary experiments were attempted using $80 \mathrm{~mol} \% \mathrm{NaO}^{t} \mathrm{Bu}$ or $10 \mathrm{~mol} \% \mathrm{NaOH}$ as the catalyst in the model reaction under the optimized reaction conditions. A 53\% yield was obtained in the former case and no desired product was detected in the latter, indicating that the reaction was promoted by the cooperation of lanthanide and sodium ions.

\section{Conclusions}

In summary, the first catalytic acylation of nitriles with esters allowing efficient preparation of $\beta$-ketonitriles in the presence of $10 \mathrm{~mol} \% \mathrm{NdNa}_{8}\left(\mathrm{O}^{t} \mathrm{Bu}\right)_{10}(\mathrm{OH})$, a heterometallic alkoxide cluster containing of neodymium and sodium, was demonstrated. Moderate to high yields were obtained using both enolizable and nonenolizable esters. Further studies on the catalytic system to examine the scope of its applications are in progress.

This work was supported by the National Natural Science Foundation of China (20872106 and 20972107).

1 Laufer S A, Zimmermann W, Ruff K J. Tetrasubstituted imidazole inhibitors of cytokine release: Probing substituents in the N-1 position. J Med Chem, 2004, 47: 6311-6325

2 Goasdoue N, Gaudemar M. Sur les organozinciques issus des $\alpha$-bromonitriles: III. Reactivite vis-a-vis des nitriles. J Organomet Chem, 1974, 71: 325-333
3 Kobler H, Schuster K, SimChen G. Synthese von nitrilen mit tetraalkylammoniumcyaniden. Justus Liebigs Ann Chem, 1978, 1946-1962

4 Beech W F, Piggott H A. 1: 2-Dicarboxylic acids. Part IV. Saturated and unsaturated dialkyl- and alkyl-aryl-dinitriles. J Chem Soc, 1955, 423-429

5 Okeda H, Taniguchi K, Enoki K, et al. Studies on sulfisoxazoles I. Syntheses of methyl $\alpha$-chloroethyl ketone and $\alpha$-acetylpropionitrile. J Pharm Soc Jpn, 1956, 76: 60-62

6 Fleming F F, Iyer P S. Cyclic oxonitriles: Synergistic juxtaposition of ketone and nitrile functionalities. Synthesis, 2006, 893-913

7 Elnagdi M H, Elmoghayar M R H, Elgemeie G E H. The chemistry of 3-oxoalkanenitriles. Synthesis, 1984, 1-26

8 Eby C J, Hauser C R. Acylations of nitriles with esters by sodium amide in liquid ammonia to form $\beta$-ketonitriles. Consideration of amidine formation. J Am Chem Soc, 1957, 79: 723-725

9 Blake J, Willson C D, Rapoport H. 3-Pyrrolidinones by intramolecular condensation. J Am Chem Soc, 1964, 86: 5293-5299

10 Kayaleh N E, Gupta R C, Johnson F. Enolate ions as $\beta$-activators of ortho-metalation: direct synthesis of 3-aminoindenones. J Org Chem, 2000, 65: 4515-4522

11 Katritzky A R, Abdel-Fattah A A A, Wang M. Expedient acylations of primary and secondary alkyl cyanides to $\alpha$-substituted $\beta$-ketonitriles. J Org Chem, 2003, 68: 4932-4934

12 Ji Y, Trenkle W C, Vowles J V. A high-yielding preparation of $\beta$-ketonitriles. Org Lett, 2006, 8: 1161-1163

13 Sheng H T, Xu F, Yao Y M, et al. Novel mixed-metal alkoxide clusters for lanthanide and sodium: Synthesis and extremely active catalysts for the polymerization of $\varepsilon$-caprolactone and trimethylene carbonate. Inorg Chem, 2007, 46: 7722-7724

14 CCDC-676721 contains the supplementary crystallographic data for this paper. The data can be obtained free of charge from the Cambridge Crystallographic Data Centre via www.ccdc.cam.ac.uk/data request/cif

15 Evans W J, Sollberger M S, Ziller J W. Synthetic and structural studies of nonametallic tert-butoxide mixed-metal complexes of yttrium, europium, and sodium: $\mathrm{X}$-ray crystal structures of a new class of $\mathrm{LnNa}_{8}(\mathrm{OR})_{10} \mathrm{X}$ complexes $\left(\mathrm{Ln}=\mathrm{Y}, \mathrm{Eu} ; \mathrm{R}=\mathrm{CMe}_{3} ; \mathrm{X}=\mathrm{Cl}, \mathrm{OH}\right)$. J Am Chem Soc, 1993, 115: 4120-4127

16 Fleming F F, Shook B C. Nitrile anion cyclizations. Tetrahedron, 2002, 58: 1-23

Open Access This article is distributed under the terms of the Creative Commons Attribution License which permits any use, distribution, and reproduction in any medium, provided the original author(s) and source are credited. 